\title{
Viaje al centro del extrarradio desde Los Chichos a Rosalía: una geografía flamenca de las periferias urbanas españolas
}

Miguel García-Martín. Universidad de Sevilla, Sevilla, España.

RESUMEN | El flamenco, como expresión cultural secularmente asociada a ciertas clases sociales desfavorecidas, ha desempeñado un papel muy relevante en la construcción de la imagen y la identidad de los paisajes de las periferias urbanas. Nuestro objetivo es trazar un recorrido por algunas de esas representaciones, vinculadas a los significados cambiantes que ha ido adquiriendo la periferia a medida que se ha modificado el medio geográfico subyacente. Así, en los años setenta y ochenta, la "música de gasolinera" puso banda sonora a la idea de marginación y delincuencia que acompaña al arquetipo quinqui. Con posterioridad, el estigma fue siendo sustituido por el reclamo de atención, se persiguió el reconocimiento social de barriadas tradicionalmente estigmatizadas y el flamenco ayudó a generar un sentimiento de autoestima. Este proceso finalizó en la resignificación del 'afueras' como espacio elogiado y vanagloriado, una suerte de empoderamiento del suburbio como un lugar apreciado, cargado de símbolos que lo cualifican.

PALABRAS CLAVE | cultura urbana, geografía social, periferia urbana.

ABSTRACT | Flamenco is a cultural expression, secularly linked to Spanish lower social classes, and has played a significant role in the construction of the image and identity of peri-urban landscapes. In this research paper, these representations are outlined, whereby meanings of suburban areas have shifted as their geographical environment has changed. Thus, in the '70s and '80s, a depiction of "quinqui" archetype as a paradigm of marginalization and delinquency was made via the "gasolinera music". Afterward, the stigma was replaced by the claims for attention, and social recognition of stigmatized neighborhoods is observed. So, flamenco contributed to the increasing of a feeling of self-worth. Finally, suburbs have undergone a particular resignification as flattered and boasted spaces; thus, a kind of empowerment and reappraising of the suburb occur through new symbolic features.

KEYWORDs | urban culture, social geography, urban periphery. 


\section{Introducción}

En 1980, en el típico magazine televisivo de sobremesa de TVE, podía escucharse al famoso presentador Joaquín Prats referirse a Los Chichos, a los que entrevistaba en directo, como "gitanos de los buenos, de los que trabajan". A lo largo de la entrevista se fueron sucediendo otros comentarios, que vienen a demostrar hasta qué punto unos rumberos gitanos procedentes de la periferia madrileńa eran tratados como agentes extrańos para la cultura oficial, por más que sus muchos discos vendidos reflejaran la enorme popularidad de la que gozaban.

Más allá de lo anecdótico, el episodio en cuestión sirve para introducirnos en el asunto de fondo. En la representación simbólica del 'afueras', del extrarradio, de los espacios suburbiales... de la ciudad periférica española, en suma, el flamenco ha desempeńado un papel muy relevante, precisamente por preservar en su génesis una condición marginal y rebelde. Canciones, letras, bandas sonoras y videoclips audiovisuales han proyectado una imagen deliberada de estos espacios, dotándolos de valores y significados que los convierten en algo más que meros decorados. Estas periferias, como espacios percibidos, connotados y simbolizados, adquieren una dimensión geográfica subjetiva que requiere que sean abordados en tanto que lugares (Cresswell, 2004; Relph, 1976; Tuan, 1974) o paisajes (Zoido Naranjo, 2001).

El objetivo de este artículo es explorar esas distintas formas de representación, indagando en los variados significados que intérpretes y audiencias otorgan al territorio liminar de la ciudad. Para ello es de utilidad el método interpretativo y hermenéutico propuesto por Ojeda Rivera (2013) para la lectura de los paisajes: un método basado en la concepción transdisciplinar propia de las geografías culturales, que trasciende las disciplinas sin renunciar a ellas ni rechazarlas, pero que pone el énfasis en lo que está entre las disciplinas, lo que las atraviesa y lo que está más allá de las mismas. Visto que el objeto de investigación se plantea complejo -el flamenco como mecanismo de representación de las periferias urbanas-, conviene abordarlo no desde un solo punto de vista, sino desde un enfoque poliédrico y amplio, que va desde campos de conocimiento más territoriales, como el propio urbanismo, hasta otros más centrados en los estudios culturales, como la crítica musical. Esto comporta asimismo métodos tanto heurísticos como inductivos, y procedimientos que oscilan entre el análisis territorial propio de los geógrafos y el análisis crítico del discurso usual de las ciencias de la comunicación.

Para ello, este texto se estructura de la siguiente manera: tras estas líneas preliminares, se abordan dos conceptos clave, como son el modelo centro-periferia y el flamenco como expresión cultural. A continuación se analizan las tres fases que, como hipótesis centrales en esta contribución, se identifican en la relación entre el flamenco y la periferia urbana: una primera fase marcada por el estigma de la marginación, la exclusión social y la delincuencia; una segunda fase de reconocimiento social y búsqueda de autoestima; y una tercera fase que orbita entre la brandificación (flamenco como etiqueta) y la apología (el elogio flamenco de la periferia). Un último apartado sirve de conclusión. Por su parte, las referencias bibliográficas se nutren, más allá de la correspondiente literatura académica, de otras fuentes 
igualmente elocuentes, como los propios temas musicales, películas o entrevistas en artículos periodísticos.

\section{El modelo centro-periferia en las escalas urbanas-metropolitanas}

Desde que Reynaud (1981) introdujera la noción de centro-periferia en los estudios geográficos, se la ha utilizado con frecuencia para explicar la oposición espacial y funcional entre las dos partes de un territorio -la hegemónica y dominadora frente a la subordinada y dominada- a diversas escalas, ya sean urbanas, regionales, o incluso a escala global. A pesar de su origen semántico, centro y periferia no obedecen necesariamente a un significado geométrico: el centro no tiene por qué estar en medio de un espacio ni la periferia en los márgenes (Cattan, 2006; Grupo ADUAR, 2000). La antinomia se establece por las funciones de dominación, poder y toma de decisiones de la primera, que recíprocamente afecta a la segunda, que se ve dependiente, dominada y relegada. Esta dicotomía responde así a "un mundo ordenado diferencialmente por el capitalismo, donde el centro y la periferia son las dos componentes de un orden social sustentado en una evidente desigualdad, tanto económica como social, política y territorial” (Hiernaux \& Lindón, 2004, p. 111). Sin embargo, para que la pareja tenga sentido, entre ambas realidades espaciales deben producirse intercambios o flujos. Esta interrelación, que es disimétrica, perpetúa la desigualdad entre las partes; y son precisamente esos déficits los que interesa estudiar para conocer el verdadero alcance de la relación (Grataloup, 2004). Como podrá comprobarse en nuestro caso, el dinamismo no se reduce a la existencia de estos flujos, sino también a la capacidad de las partes para moverse, cuando ocurre que se convierten en nuevas centralidades determinados lugares (o algunas de sus cualidades) antaño marginales.

Si bien este modelo puede quedar en entredicho cuando se aplica a escala mundial como sinónimo del sistema de dominación Norte-Sur, a las escalas urbanas y metropolitanas sigue teniendo suficiente vigencia. Eso sí, reconociendo ciertas limitaciones en tanto que modelización de una realidad más compleja y heterogénea. En el caso español, y desde la perspectiva de la geografía urbana, las periferias de las grandes ciudades adquieren su dimensión tal y como hoy las conocemos a partir de la segunda mitad del siglo xx (Mas Hernández, 1999; Nel.lo, 2004; Valenzuela Rubio, 1989). Si bien la dualidad entre una ciudad central y planificada de inspiración burguesa y una periferia proletaria espontánea va cimentándose desde el inicio de los planteamientos urbanísticos modernos, vigentes ya desde mediados del siglo XIX, será tras la posguerra cuando se asista al definitivo surgimiento de importantes barrios y barriadas de clases bajas más allá de los contornos de la trama urbana. En un primer momento, durante el periodo autárquico (décadas de los ańos cuarenta y cincuenta), sobresalen los asentamientos marginales de viviendas de autoconstrucción, carentes de los más elementales servicios urbanos (luz, agua potable, alcantarillado, pavimentación, etc.): Palomeras, El Pozo del Tío Raimundo (Madrid); Somorrostro, Pekín o Campo de la Bota (Barcelona) son ejemplos ilustrativos. En las décadas posteriores, durante el periodo desarrollista de los años sesenta y setenta, se levantaron o se terminaron de consolidar multitud de polígonos residenciales: 
barriadas de bloques abiertos de viviendas de promoción pública e inspiración racionalista, concebidos para alojar a una creciente población inmigrante procedente de las regiones peninsulares menos desarrolladas, cuyas condiciones de habitabilidad darían lugar, en palabras de Valenzuela Rubio (1989), a un "permanente estado de frustración, traducido en conflictividad social” (p. 145). Buen ejemplo de ello son las populosas barriadas de Orcasitas (Madrid), Bellvitge (Barcelona), Polígono San Pablo (Sevilla), Palma-Palmilla (Málaga) o Almanjáyar (Granada). En efecto, emergieron como grandes bolsas residenciales, densamente habitadas por una población obrera modesta, pero originariamente mal articuladas con el resto de la ciudad y muy limitadas en cuanto a dotaciones y servicios (Fernández Salinas, 1998; García Vázquez, 2015; Piñeira Mantiñán, 2010).

Con el tiempo, estos sectores residenciales han acabado por incorporarse a la trama urbana consolidada, con mejores o peores soluciones de vertebración con el resto de la ciudad y mejoras dotacionales de distinto éxito, según los casos. También se observa una maduración del tejido social, toda vez que las segundas (y siguientes) generaciones, ya sí nativas, hacen germinar sentimientos de pertenencia al lugar que refuerzan los lazos de identidad entre la comunidad y el barrio (Pareja Eastaway \& Simó Solsona, 2006). La dimensión metropolitana que adquiere el proceso urbanizador desde finales del siglo xx podría, sin embargo, poner en entredicho la condición periférica de estos sectores urbanos, visto que, con el cambio de escala, los bordes se vuelven difusos y se pierde la referencia -física y conceptual- de lo que son los límites de la ciudad. Sin embargo, en tanto que espacios subsidiarios, jurídica y simbólicamente dependientes de una centralidad urbana, su condición periférica sigue estando presente, como se pondrá de manifiesto a lo largo de esta contribución.

\section{El flamenco: ¿̨condición periférica?}

El flamenco, como manifestación cultural folclórica, de origen popular, ha estado históricamente condicionado por su naturaleza periférica, por más que en la actualidad muchos de sus creadores e intérpretes lo hayan elevado con merecimiento a la categoría de arte universal. Prescindiendo de una primitiva etapa hermética de su historia, que ofrece más sombras que luces, los primeros testimonios conocidos que hacen referencia al cante o al baile flamenco se vinculan con una clase social desheredada en la baja Andalucía (Gamboa, 2005). Estas expresiones musicales son, por tanto, el resultado de las transformaciones sociales y económicas en el mundo industrializado entre finales del siglo xvin y principios del xIx: en el contexto de un nuevo modelo de producción capitalista, tanto en el campo como en la ciudad emerge una clase social, jornalera y proletaria, que heredará viejas prácticas para confeccionar las fórmulas y los estilos que hoy conocemos (Álvarez Caballero, 2004; Steingress, 1993).

Esta condición periférica del origen e inicios del flamenco puede examinarse desde diversos puntos de vista. Desde una perspectiva social, cante y baile flamencos han estado vinculados a los grupos más desfavorecidos, entre los que cabe mencionar a los propios gitanos. Grimaldos Feito (2010) afirma intencionadamente que "en las letras flamencas hay un poso de rebeldía, fruto de la persecución y la marginación” 
(p. 16). Este mismo autor recoge los testimonios de los hermanos Caba, estudiosos flamencos que en plena Segunda República manifestaban que el verdadero cante jondo había que sondarlo "en el campesino solitario, en el recluso de la penitenciaría, en la mujer del prostíbulo o en el obrero de la mina” (p. 58).

También desde una perspectiva mediática y artístico-musical, el flamenco ha estado históricamente excluido del selecto círculo de las músicas consideradas cultas, precisamente por su naturaleza popular como una expresión folclórica catalizadora de costumbres y tradiciones. Por ello mismo, su lugar, alejado de las instituciones oficiales -representadas en los paradigmáticos auditorios, óperas o concert hallsvenía siendo en origen el patio de vecinos, la venta, la calle, la taberna... aunque bien es cierto que, con posterioridad, los flamencos dieron el salto a los tablaos y festivales veraniegos, y de ahí han pasado a la conquista de los grandes teatros. Pero esta transición desde los márgenes periféricos a la centralidad musical no se ha producido hasta tiempos relativamente recientes, y solo para ciertas categorías más convencionales del cante, baile y toque flamencos. Buen ejemplo de ello lo constituye el grupo Camela, una formación musical de estilo pop y electrónico, pero con influencias de la rumba y el flamenco. A pesar de las enormes cifras de ventas que han manejado desde mediados de los años noventa, han padecido una discriminación cultural y mediática por parte de las elites que controlan el discurso musical oficial -emisoras de radio, programas televisivos, periodistas, gestores culturales, etcétera-, que los ha relegado a una posición marginal (Lenore, 2014; López Castellano, 2019; Paskual, 2013).

También desde una perspectiva geográfica y espacial el flamenco se ha situado en los márgenes, cualquiera que sea la escala de interpretación territorial. Partiendo de un ámbito más general, esta música, al proceder de regiones periféricas del "Sur" -Andalucía, pero también la Extremadura más meridional o la comarca minera de Cartagena y La Unión, en Murcia- arrastra todas las connotaciones culturales y económicas que ello implica frente a la posición dominante que ostentan las regiones espańolas "centrales" (Cruces Roldán, 2003). Y en una escala de mayor detalle, en los ámbitos urbanos y metropolitanos, el flamenco, ya desde su origen, se ha preservado y perpetuado en los arrabales históricos y con posterioridad en barriadas obreras y en polígonos residenciales de las grandes aglomeraciones urbanas españolas, ${ }^{1}$ amparado en los estrechos círculos asociativos que se originan en torno a la familia, la vecindad y la comunidad (Cruces Roldán, 2002). Serán precisamente estos espacios los más interesantes desde la perspectiva que adoptamos en esta contribución, que al fin y al cabo pretende examinar la forma en que ciertas manifestaciones flamencas producen y reproducen una imagen y un discurso deliberado en torno a determinados territorios urbanos en la frontera.

1 Sin olvidar los ámbitos rurales, donde el flamenco encontró un importante foco germinal en una masa depauperada de jornaleros propia de la Andalucía latifundista; o los territorios mineros, igualmente dependientes de mano de obra asalariada. 


\section{El estigma de la marginación, la exclusión social y la delincuencia}

El punto de partida en este recorrido geográfico e histórico por la imagen de la periferia urbana se sitúa aproximadamente en la década de los setenta, en un momento en que las ciudades españolas experimentan una transformación muy significativa: se trata del cambio en el modelo socioeconómico y demográfico que acompaña al periodo desarrollista, que en lo espacial se traduce en un importante crecimiento y concentración de la población urbana. Es asimismo cuando, a través de los medios de comunicación de masas, se consolida una industria cultural al servicio de las clases medias y trabajadoras (Gámir Orueta, 2004): el mejor ejemplo lo protagoniza el radiocasete, un soporte que favoreció el despegue de muchas formaciones y la consecuente popularización y distribución de sus diversas propuestas musicales (Bautista Sánchez et al., 2013; Gallego, 2016).

Durante estos años, en las barriadas y extrarradios de las grandes ciudades, el flamenco va a operar como un mecanismo de representación de los fenómenos de estigmatización que allí se venían padeciendo: marginación, delincuencia, decadencia social, abandono, etcétera. Es en estos barrios donde emergen formaciones musicales que transmiten en las letras de sus canciones una mezcla de desamparo, opresión, denuncia, o incluso rebeldía, aunque también se manifiesta por medio de esta música el desarraigo y la nostalgia propios de las comunidades migrantes. ${ }^{2}$ Las aglomeraciones urbanas de Madrid y Barcelona resultan ser ejemplos paradigmáticos.

En primer lugar hay que destacar el cinturón sur de Madrid -aquello que se extiende más allá de la denominada "línea de pobreza" identificada por Temes (2014)-, que a lo largo de las últimas décadas ha concentrado la mayoría de los barrios con los índices de vulnerabilidad territorial, pobreza y exclusión social más elevados de toda la aglomeración urbana (Ayuntamiento de Madrid, 2018; Ministerio de Fomento, 2019). Allí surgen grupos como Los Chichos y Los Calis (Pozo del Tío Raimundo), Los Chunguitos (Vallecas), Los Chorbos y Las Grecas (Caño Roto), etcétera. Estas formaciones saben captar en sus letras el dolor y el sobrecogimiento que se padece en estos espacios estigmatizados y transmitirlos así en su música (Urrutia Valenzuela, 2007). Los Calis (1986a) reflejan los estragos de la drogodependencia en su célebre "Heroína": "Más chutes no/ ni cucharas impregnadas de heroína/ No más jóvenes llorando noche y día/ solamente oír tu nombre causa ruina”. La cárcel es otra constante entre estos grupos musicales, que reflejan en canciones como "Quiero ser libre" (Los Chichos, 1974) o "Libertad para ti" (Los Calis, 1986b) el padecimiento de una clase obrera depauperada que se ve obligada a delinquir, mostrada más bien como víctima de un orden social descompensado e injusto.

El cine ha demostrado ser también un instrumento muy elocuente de reinterpretación del mundo urbano, en especial al evidenciar los claroscuros del urbanismo racionalista, funcionalista aunque en muchas ocasiones deshumanizador (Costa

2 Como así se pone de manifiesto en algunos temas como "Bailarás con alegría" (Los Chichos, 1981) o "Del Sur a Cataluña" (Tijerita, 1986), donde se hacen alusiones explícitas a Andalucía como lugar ańorado. Estos autores encarnan el desarraigo de los emigrantes del sur peninsular, una diáspora que reproduce en el exilio una imagen simbólica e identitaria de Andalucía sobre la que se construyen los sentimientos colectivos de pertenencia. 
Mas, 2003; Gámir Orueta \& Manuel Valdés, 2007). La periferia madrileña y barcelonesa quedará reflejada en muchas de las películas que constituyen el denominado cine quinqui, cuyas bandas sonoras fueron encargadas e interpretadas precisamente por representantes de las corrientes más pop del flamenco y la rumba. La rumba flamenca, como estilo musical propio, adquiere un papel esencial en las narrativas audiovisuales de estas películas. Alfeo Álvarez y González de Garay Domínguez (2011) lo manifiestan en semejantes términos, al afirmar que las canciones que constituían el acompańamiento musical, "lejos de ser anecdóticas o simplemente una marca de estilo, desgranaban y reforzaban el mensaje de denuncia social que servía de trasfondo a las tramas en relación con cuestiones como la droga, la delincuencia juvenil o los desajustes del sistema judicial” (p. 795). La película Deprisa, deprisa, de Carlos Saura (1981), muestra de forma ejemplar la dialéctica entre la ciudad central y la periferia como metáfora de los distintos arquetipos sociales que protagonizan la historia, correspondiendo el último al paria marginado que vive en los límites físicos y existenciales de la sociedad (Whittaker, 2008). El uso constante del descampado como escenario resulta esencial no solo desde el punto de vista estético, sino también narrativo (Camiñas Hernández, 2013; Labanyi et al., 2012), a lo que hay que sumar la banda sonora, interpretada por Los Chunguitos, Lole y Manuel y otros intérpretes de marcado carácter flamenco. Como ponen de manifiesto diversos autores (Fraile Prieto, 2013; Leal García, 2018; Willem, 2008), por encima de otros géneros musicales como pudieran ser el rock o el punk, el flamenco resultará ser el estilo que mejor caracterice el modo de vida marginal, oprimido y rebelde de los protagonistas. En parte, ello se justifica en la propia procedencia humilde de los grupos musicales, muchos de los cuales tienen su origen precisamente en estas mismas barriadas que sirven de marco geográfico y de contexto narrativo a las películas del cine quinqui de la Transición.

Por su parte, la película Yo, el Vaquilla (Loma, 1985) -cuya banda sonora interpretan Los Chichos (1981) - detiene con particular atención su mirada en el barcelonés barrio del Campo de la Bota, momento que aprovecha el cineasta para crear un paréntesis diegético y cambiar el registro narrativo ficcional e introducir una secuencia de tipo documental. Se testimonian así los últimos momentos de existencia de este barrio de barracas del norte de la ciudad, prototipo de asentamiento chabolista informal muy deprimido. El Campo de la Bota se originó hacia la segunda mitad del siglo xix, cuando empezó a poblarse con inmigrantes de diversa procedencia, desplazados por el éxodo rural. Durante los años sesenta y setenta llegó a albergar una población estimada de 4.500 personas, en su mayoría gitana (Monferrer i Celades, 2013). La canción que ambienta el momento en que los protagonistas acceden al Campo de la Bota condensa acertadamente el mensaje de estigmatización y exclusión social que caracteriza esta fase: "aquí tan solo se compra y se vende (...). Aquí mueren los chivatos, a los chivatos nadie los quiere”.

\section{El reconocimiento social y la búsqueda de autoestima}

A finales de la década de los ochenta se desmantelaron las últimas barracas del Campo de la Bota y -al igual que ocurriera con otros asentamientos irregulares barceloneses, 
CEURE | VOL 48 | $\mathrm{N}^{\mathrm{O}}$ I43 | ENERO 2022 | pp. I-20

como Pekín o Somorrostro- la población fue realojada en el vecino barrio de La Mina, un sector residencial de grandes bloques de vivienda vertical entre los municipios de Barcelona y Sant Adrià de Besòs. En la actualidad, La Mina está integrada en el barrio El Besòs i el Maresme. Esta profunda transformación físico-espacial finisecular se hace asimismo patente en el nuevo significado que el flamenco adquiere como mecanismo de autorrepresentación social. Y es que no parece casual que el centro cívico del Besòs tenga precisamente al flamenco como leitmotiv:

Música, teatro, danza, exposiciones... las actividades del Centro Cívico Besòs son muchas y muy diversas, pero el eje de su programación gira en torno al flamenco. La formación, el apoyo a la creación y la difusión son las tres líneas de actuación del Centro Cívico respecto a la cultura flamenca, que se traducen en la creación de una escuela de flamenco, la organización de unas residencias de creación y la programación de espectáculos. (Ayuntamiento de Barcelona, 2019)

Este caso ilustra bien el proceso evolutivo por el cual se transita desde esa primera fase marcada por la estigmatización, hacia una segunda caracterizada por la búsqueda de reconocimiento social y la intención de proyectar una imagen dignificada basada en la autoestima. El flamenco va a funcionar en estos casos como elemento de reafirmación identitaria, incluso como palanca de transformación social. Ya sea "desde arriba" (desde las administraciones públicas municipales) o "desde abajo" (los propios colectivos vecinales), se hace uso de esta expresión cultural para llevar a cabo proyectos de cooperación al desarrollo, programas educativos y otras soluciones políticas de integración y cohesión social.

Aunque antes se ha mencionado el caso de La Mina, en Barcelona, probablemente el ejemplo más paradigmático de esta segunda fase haya que buscarlo en el Polígono Sur, en Sevilla. Este barrio fue constituyéndose en diversos periodos, desde mediados de la década de 1960 hasta principios de la década de 1980, como respuesta planificada ante los no pocos problemas de vivienda de diversa naturaleza que se venían padeciendo en la ciudad. Por un lado, los afectados por las últimas inundaciones -desbordamiento del arroyo Tamarguillo en 1961- fueron realojados en este nuevo barrio tras haber pasado por algunos de los muchos pabellones temporales que se improvisaron en distintos edificios y naves de la ciudad (Salas, 2017). También se trasladaron allí familias que, procedentes principalmente del éxodo rural, habían levantado asentamientos irregulares muy precarios diseminados por los alrededores de la capital. Pero también se acabó por realojar a las familias que procedían del casco antiguo y de otros barrios históricos, como Triana, muchas de las cuales seguían habitando los populares corrales de vecinos, obligadas a abandonar estas viviendas colectivas por el estado ruinoso en que se encontraban (Llácer Moreno-Aurioles, 2015). Así, el Polígono Sur fue experimentando un progresivo estado de deterioro y marginación social, que Torres Gutiérrez (2013) identifica a partir de cuatro etapas: una primera fase, hasta los años ochenta, en la que esta barriada se constituirá como un contenedor de pobres, esto es, una fuente de mano de obra disponible y barata; una segunda etapa (1981-1992), en la que el barrio muta hacia un contenedor de población excluida, donde se empieza a experimentar el declive social; un tercer momento (1992-2003) de agudización de la marginación y el estigma; y una cuarta y -hasta 
la fecha- última etapa de intento de reversión, que desemboca en la creación del Comisionado para el Polígono Sur, como resultado de las reivindicaciones vecinales y la propia iniciativa pública (nacional, autonómica y municipal).

Todos los inconvenientes que arrastra esta barriada -lo que ha acabado por convertirla en un prototipo de exclusión urbana a escala nacional-, contrasta con el importante potencial artístico y musical que subyace en algunos de sus habitantes, cualidad reflejada por algunas producciones audiovisuales que no han pasado por alto esta aparente paradoja. El flamenco compite como una seńa de identidad positiva frente a la imagen peyorativa y muy mediatizada que se ha construido desde fuera. En efecto, muchas dinastías y artistas proceden de este barrio, algunos de ellos autores de relevancia en el panorama musical español contemporáneo, como es el caso de los hermanos Amador (fundadores de la mítica banda Pata Negra). El documental Polígono Sur: El arte de Las Tres Mil, de Dominique Abel (2003), ofrece una mirada inicial a este fenómeno. Esta película, a medio camino entre el cine documental performativo (Nichols, 2001) y el relato biográfico semificcional de los artistas del barrio, proyecta una mirada poliédrica sobre la relación entre el flamenco y la marginación social. Así, este arte es representado en la película como un aglutinante identitario que ayuda a que circulen las relaciones afectivas entre los distintos miembros de la comunidad (Van Tongeren, 2017). Más allá de las posibles críticas por el tratamiento edulcorado, cuando no soslayado, de los problemas serios que afectan al barrio, esta producción audiovisual marca un primer punto de inflexión, al dotar a sus habitantes de la capacidad propia para autorrepresentarse y enfrentarse así a clichés exógenos. El flamenco actúa como el capital humano que hace posible esa marca de distinción cultural, artística y urbana.

Con posterioridad, otros documentales han permitido visibilizar los diversos esfuerzos que desde la colaboración institucional-vecinal se han llevado a cabo en los últimos años en el Polígono Sur para mitigar los problemas de marginación y de vulnerabilidad social, con el flamenco como palanca de transformación. Alalá (alegría), dirigida por Remedios Malvárez (2016), muestra el proyecto de Emilio Caracafé, guitarrista procedente del barrio que fundó una escuela de arte con el objetivo de transmitir a los adolescentes valores ciudadanos y un sentido de la autoestima a través del toque, el cante y el baile flamencos. Al igual que en el caso anterior, el Polígono Sur actúa aquí como algo más que un mero decorado espacial. La poderosa carga visual de su paisaje y su fisonomía urbana pretende crear en el espectador un "efecto paradoja": la riqueza, el talento y la virtud de las personas (los alumnos, los maestros, los colaboradores, el resto de personajes asociados...) contrastan con el deterioro y la pobreza de las calles y los edificios, dignificando a sus habitantes por encima del lastrado y deteriorado espacio físico.

A todo lo anterior hay que añadir otros proyectos similares surgidos en el Polígono Sur desde la Factoría Cultural, una dotación pública gestionada por la administración municipal en colaboración con las asociaciones ciudadanas. En dichos proyectos se apuesta por el flamenco para el desarrollo de una política cultural que favorezca la integración del barrio en el resto de la ciudad y focalice las iniciativas creativas e innovadoras con base en su tejido social. Los responsables municipales de esta dotación la definen en tales términos, al afirmar que la Factoría Cultural pretende 
hacer de vehículo a la cultura al mismo tiempo que ofrece una alternativa al estereotipo. Al sambenito que sufre esta zona. Además de ofrecer un relato personal y así contribuir a que el barrio se autorrepresente y cree su imagen propia. Este lugar tiene una serie de particularidades a nivel cultural. Dentro de que es muy heterogéneo y diverso, presenta unas cualidades impresionantes (...). Es difícil, pero este barrio es luchador y lucha con uñas y dientes contra él. Es muy ilusionante ver cómo la gente al final siempre reclama que se les respete y dignifique. (Madrigal, 2019)

El último de los proyectos de la Factoría Cultural, el encuentro "Campus Polígono Sur. Arte y contexto en la periferia”, ${ }^{3}$ profundiza una vez más en esta idea con su obra finalista, el videoclip Aquí Polígono Sur, que parece verse impelida por el poderoso influjo de lo flamenco como forma de identificación con esta periferia, por más que el estilo elegido para conducir el mensaje sea el rap.

\section{Más allá de la autoestima: entre la etiqueta flamenca y la apología del 'afueras'}

Precisamente el rap (y, en un sentido más amplio, la cultura hip-hop) comparte muchos de los significados que en su relación con los espacios urbanos periféricos se detectan en el flamenco. Si en otras latitudes el rap se comporta como una manifestación de reafirmación identitaria de las minorías raciales o religiosas en los ghettos americanos y las banlieues del centro y norte de Europa (Dotson-Renta, 2015; French, 2017; Tickner, 2008), en España muchos raperos han visto en el flamenco un factor sinérgico, un catalizador para hacer más ostensible su particular narrativa.

Uno de los primeros intérpretes en apelar al flamenco como tarjeta de presentación fue Haze, un MC sevillano que en multitud de ocasiones se ha definido (o ha sido definido por terceros) $)^{4}$ como un rapero flamenco. En 2003 grabó sus primeras maquetas, por entonces autoeditadas y sin sello de distribución, entre las que se encuentra el tema "Los Pajaritos", toda una declaración de intenciones sobre el nuevo papel que iban a desempeñar estos sonidos urbanos en la resignificación de las periferias obreras (Conget, 2017). En la canción, Haze se pregunta "dónde se escucha [su] rap", como fórmula retórica para detallar las muchas barriadas de Sevilla con las que se identifica afectivamente. Lo relevante en este caso es que, si se lee entre líneas, se observa una voluntad intrínseca de desmarcarse de la ciudad central burguesa, de renunciar a ella como aspiración, para situarse simbólicamente en la periferia. Consciente de su carga semántica, el rapero recurre a una enumeración constante y copiosa de topónimos que hacen referencia intencionada a esos

3 En este proyecto también han colaborado instituciones como la Universidad Pablo de Olavide o la Fundación SGAE, lo que confirma que entre las centralidades, en este caso culturales, y las periferias como lugares de la creación existen flujos constantes de ida y vuelta que complejizan el modelo inicialmente expuesto y desaconsejan, en consecuencia, una visión excesivamente reduccionista del mismo. Sobre "Campus Polígono Sur. Arte y contexto en la periferia", del Ayuntamiento de Sevilla, puede verse "El Polígono Sur sube al escenario con la Fundación SGAE", 18/oct/2019, en http:// www.sgae.es/es-ES/SitePages/EstaPasandoDetalleActualidad.aspx?i=4031\&s=5

4 Véanse las entrevistas en distintos medios de comunicación, como 20 Minutos, El Español o ABC de Sevilla (Álvarez, 2019; Arenas, 2016; Maldonado, 2018). 
barrios que cualquier habitante de Sevilla asociaría con lo popular, lo obrero, lo humilde, incluso lo estigmatizado y lo marginal (Iglesias Pascual, 2015). La Figura 1 recoge, por medio de un ilustrativo mapa, la localización geográfica de los barrios mencionados en el tema. La periferia adopta en tales casos un significado que va más allá del simple proceso de dignificación visto en la fase anterior. Ahora se trata de estimarla por encima o más allá de otros territorios de la ciudad; atribuirle una cualidad distintiva, que la enfrenta por oposición a aquellos barrios de las clases medias o acomodadas que no son merecedores de recibir el favor de que allí "se escuche [su] rap".

Figura I | Barrios de Sevilla enumerados en "Los Pajaritos”, de Haze (2003)

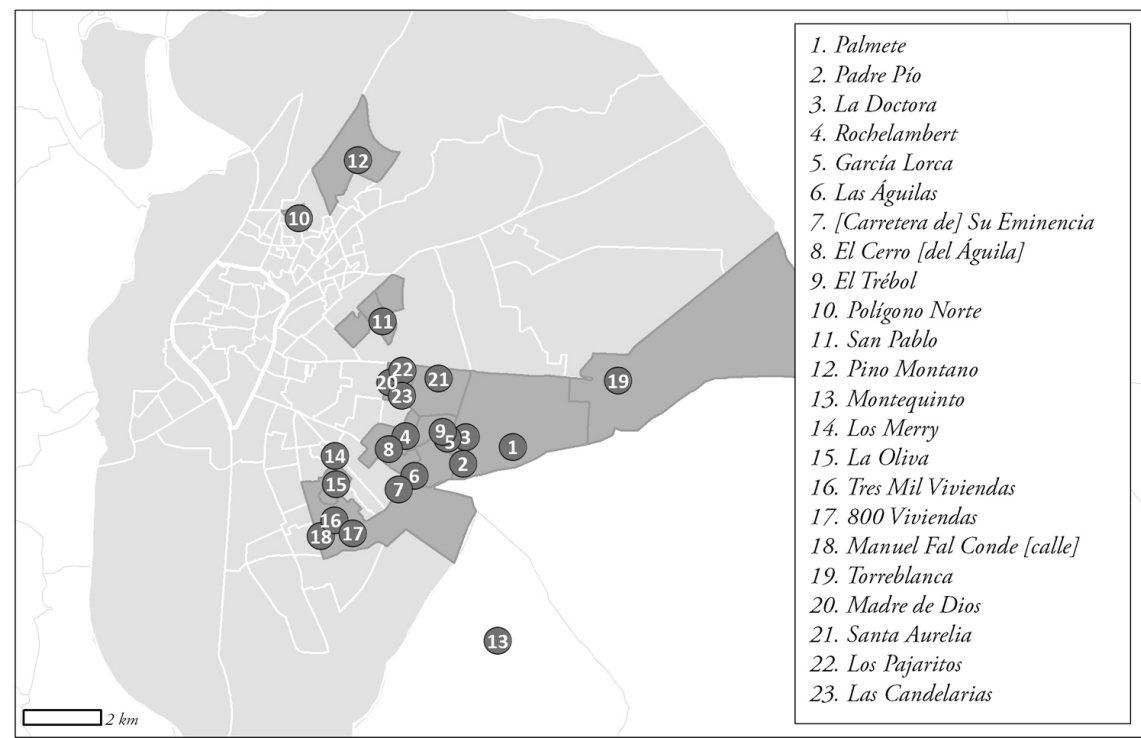

FUENTE: ELABORACIÓN PROPIA

Por su parte, Mala Rodríguez, en tanto que rapera procedente del sur, también ha sido encasillada dentro de este taxón tan sui géneris como es el rap flamenco. Si bien su propuesta en lo musical carece de aportaciones flamencas consistentes, el contexto cultural en el que se desarrolla favorece su adscripción a esta categoría. En su tema "La Niña" (Mala Rodríguez, 2003) también se percibe la idea de la centralidad urbana remota, como un lugar distante, separado del hogar suburbano donde habita la protagonista (en el sentido más cartesiano del término) por una barrera simbólica:

Esta es la historia de una nińa que vivía en el barrio de la Paz.

De ella se decía que quería vender droga como su papá.

Por ella nadie apostaba, 
su futuro se nublaba

y no había hecho más que empezar.

Quién no quiere dinero, dime,

quién no quiere dinero

pa' gastarlo en la ciudad.

Así las cosas, en los últimos años han surgido intérpretes que, como parte de la escena underground que se desarrolla en estos barrios y polígonos obreros de las grandes ciudades españolas, se han arrogado el concepto de flamenco -aquí derivado en etiqueta- para utilizarlo como un marchamo con el cual proyectar una imagen distintiva y diferenciadora. Vistos los considerables atributos y significados que se asocian al flamenco como una expresión cultural de raíz popular (véase, por ejemplo, lo genuino, la garra, el sentimiento, la pasión, la lucha, la pena, el sacrificio, el sufrimiento, lo transgresor, lo visceral...), los intérpretes los aprovechan como parte de su proyección pública en beneficio propio. A ello han contribuido igualmente las nuevas formas de promoción basadas en internet (YouTube, Vimeo, Spotify), que reducen los costes de edición y distribución, diluyendo la frontera entre la creación amateur y la producción profesional.

Se pueden encontrar en la web, por tanto, autores y formaciones de rap, trap y otros estilos similares que se etiquetan en mayor o menor medida con el apelativo 'flamenco'; y que, por nombrar tan solo algunos, serían: El Jincho, procedente del barrio de Orcasitas (sur de Madrid); Dani Jaleo, de El Ruedo (Moratalaz, Madrid); Vacie Records, de El Vacie (Sevilla); Maka, de Almanjáyar (Granada); Dellafuente, de Armilla (Granada); Nyno Vargas, de 613 Viviendas (Burjassot, Valencia); Los Santos (antiguamente PXXR GVNG), con miembros procedentes de El Realejo (Granada) o Carabanchel (Madrid), pero funcionando desde Barcelona, etcétera.

En sus videoclips, como parte de la cuidada construcción de una imagen particular y distintiva, se reconoce una serie de rasgos comunes. Por un lado, hay referencias muy explícitas al lugar de origen proletario y humilde de los intérpretes. En sus letras se "canta al barrio", poniendo el énfasis en su condición urbana periférica y marginal. Todo ello implica un acompańamiento escenográfico con multitud de elementos y atributos callejeros: el descampado, el bloque de viviendas de promoción pública, el mercadillo, el culto al coche, etcétera. A diferencia de otras músicas "atópicas" (es decir, ubicuas, carentes de referencias al lugar), en el rap flamenco y sus múltiples derivadas estilísticas el paisaje tiene mucha presencia, como proceso de connotación y representación de un territorio que se percibe subjetivamente.

Por otro lado, las biografías de los autores están cargadas de alusiones a un pasado conflictivo y problemático, a tensiones emocionales que desprenden ciertas resonancias románticas. A su vez, hay un discurso muy patente de connivencia y coqueteo con lo clandestino y lo prohibido (muy claro, por ejemplo, en el simbólico protagonismo que algunos cantantes les dan a los porros). Como parte de una aparente conciencia de clase lumpenproletaria, los cantantes muestran un rechazo a las normas institucionales, a un poder difícil de identificar, exhibiendo su predilección por transgredir los códigos de conducta del normativo ciudadano burgués. 
Es también muy significativa la abrumadora masculinidad que proyectan estos videos, encarnada ya no solo en el propio intérprete, casi siempre varón, sino en el círculo cercano y cerrado de hombres que lo acompañan, una suerte de acólitos que rodean, custodian y protegen al protagonista al igual que una manada. La mujer está desplazada, invisibilizada, lo que supone, por omisión, una condición ciertamente machista de sus narrativas. Eso sí, sin llegar a apreciarse la misoginia explícita que caracteriza a otros estilos musicales. ${ }^{5}$

Por último, llama la atención el forzado intento que se aprecia en casi todos estos intérpretes por asimilarse a lo flamenco, intención que se manifiesta en la recurrencia simplista y maniquea a Camarón. En efecto, como parte de un mecanismo de apropiación simbólica, los cantantes se arrogan el concepto de flamenco para identificar y caracterizar su estilo y su proceso creativo. Pero cuando son interrogados por sus referentes musicales flamencos, en sus declaraciones se descubre un desconocimiento desconcertante de otros autores más allá del universal cantaor isleño. ${ }^{6}$ Cabe preguntarse aquí si la apropiación cultural del flamenco viene motivada por razones estrictamente musicales. $\mathrm{O}$ si, por el contrario, se utilizan sus significados contextuales, entre los que sobresale la vinculación simbólica del flamenco con lo marginal o lo oprimido, pero también con la cultura pop(ular) o la transgresión creativa, tan nítidamente encarnada en la figura prototípica de Camarón de la Isla.

Por el contrario, existen escasos aunque muy significativos ejemplos de una relación entre el flamenco -con consistencia- y la periferia que va más allá de los procesos de búsqueda de un reconocimiento social y de una imagen dignificada basada en la autoestima, que se han visto con anterioridad y que superan la apropiación artificiosa del flamenco como pretexto y como etiqueta de la que tan recurrentemente han hecho uso los raperos. En tales casos, se asiste a una fase ulterior y mucho más madura en la que la periferia adquiere nuevos significados a través de la imagen proyectada que de ella hacen artistas y cantantes por medio de sus creaciones audiovisuales.

El mejor ejemplo de ello lo constituye Rosalía y su segundo trabajo discográfico El mal querer. Lanzados como sencillos en formato de video, "Malamente (Cap. 1: Augurio)" (2018a) y "Pienso en tu mirá (Cap. 3: Celos)" (2018b) acumulan respectivamente más de 100 y 50 millones de visitas en su canal oficial de YouTube en poco menos de ańo y medio, lo que ha lanzado a la artista al estrellato internacional. El disco se inspira en un romance occitano del siglo xiII sobre amor, maltratos y celos, cuya sorprendente vigencia se aprovecha para construir un alegato liberador y feminista (Covarsí Carbonero, 2010; Espadaler, 2019). Por medio de su propuesta musical y flamenca, Rosalía eleva el 'afueras' a un nuevo estatus: practica una auténtica apología de la periferia. Y es que, como apuntan diversos autores (Gómez Lizarraga, 2018; Morales Gálvez, 2020; Palomares Navarro \& Vives López, 2019), la cantante dota de un nuevo significado a toda la simbología religiosa, cultural y

5 Tal es el caso del reggaetón, cuyo sexismo manifiesto es analizado en Araüna et al. (2019), Carballo Villagra (2006) o Samponaro (2009).

6 Véanse, por poner algunos ejemplos ilustrativos, las distintas declaraciones vertidas en prensa por raperos como Maka, Dellafuente, Josele Junior, Daviles de Novelda, Nyno Vargas o PXxR GVNG (Becerra, 2015; Cappa, 2016; Cruz, 2018; Gómez, 2018; Oulios, 2019; Serrano, 2019). 
artística española a través de una iconografía que bebe de esta simbología, pero que la reinventa. Y ese proceso de reinvención se materializa a partir de unos significantes que son genuinamente suburbiales y, por tanto, subculturales. Consagra la periferia hasta convertirla en un elogio del extrarradio, del polígono, de la barriada, de la frontera... La cantante catalana otorga tal protagonismo a la periferia que la convierte en un personaje principal de todo su aparato iconográfico, que funciona en armonía con la música. Lo visual y lo sonoro, lo audiovisual como conjunto, se engranan en un todo.

Así, estos videoclips encadenan sus distintas secuencias a través de múltiples planos en los que aparecen gasolineras, descampados, aparcamientos de grandes superficies comerciales, intersticios de carreteras o simples callejones que sirven de biotopo a los transportistas con sus icónicos camiones, las carretillas elevadoras, las reuniones de coches tuneados, los moteros, etcétera. Y ello sin olvidar la propia estética corporal basada en los objetos fetiche: el chándal, la bisutería de oro, los aros, las uñas postizas, etcétera (Figura 2); idea que, por otro lado, se repite en el tema "Amarrao", del dúo madrileńo Sweet Barrio (2019), una formación que, desde una mezcla ecléctica de estilos que no excluye al flamenco, reivindica el culto a la estética de barriada obrera: "Cuando tenga dinero, me compro un chándal nuevo".

Figura 2 | Videoclips de "Malamente (Cap. 1: Augurio)" y "Pienso en tu mirá (Cap. 3: Celos)”, de Rosalía (2018a y 2018b)
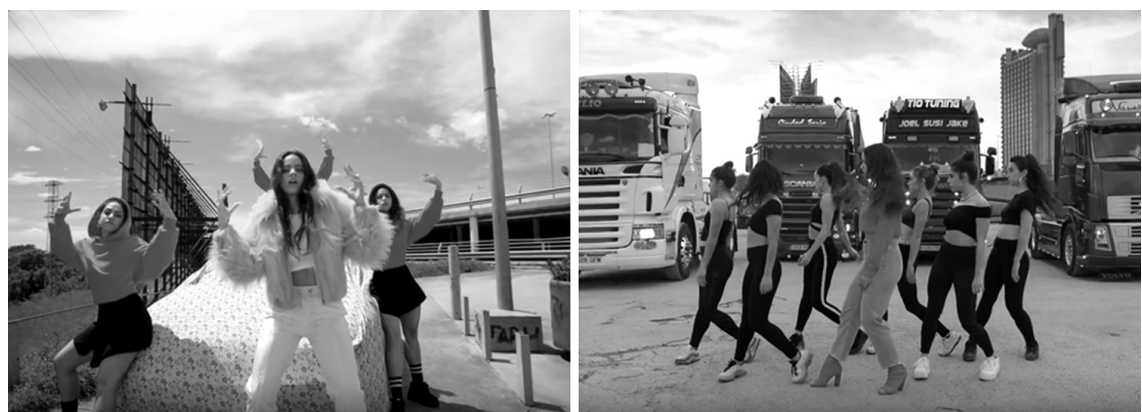

FUENTE: ROSALÍA (20 I 8A Y 20 I 8B)

En definitiva, frente a la nómina de artistas que en los últimos ańos recurren al flamenco como un envoltorio con el que disfrazar su discurso intencionado de "chico de barrio", surge una nueva generación -con Rosalía a la cabeza- que, aprovechando las enormes posibilidades creativas que ofrece el flamenco, lo reinterpreta en consonancia con el poder semántico de la periferia para generar una propuesta mucho más coherente y sofisticada.

\section{A modo de conclusión}

La geografía como ciencia social ha privilegiado ciertos enfoques a la hora de abordar el clásico antagonismo centro/periferia. Las tradicionales perspectivas 
geométrico-espacial (ocupación de suelo, expansión y fragmentación urbana, etc.) y económico-social (pobreza, segregación y exclusión, acceso a la vivienda, calidad dotacional y medioambiental, etc.) han soslayado el enfoque más centrado en las dimensiones simbólicas, las construcciones y prácticas sociales, las representaciones culturales (musicales, audiovisuales...) y la conformación de identitarios basados en esa misma naturaleza marginal y periférica. Y no sería por una falta de legitimidad epistemológica, pues las aproximaciones que desde las geografías culturales se hacen de estos temas suelen resultar bastante fecundas, como hemos tenido ocasión de comprobar.

En este sentido, el paisaje y el lugar, como ejes conceptuales dentro de las ciencias sociales, en general, y de la geografía, muy en particular, están significativamente presentes en el flamenco. A diferencia de otras manifestaciones musicales o audiovisuales ubicuas o incluso atópicas, las distintas expresiones en la órbita de lo flamenco transmiten una idea determinada del medio geográfico de donde surgen, sea este una campińa de cereal, un arrabal bajoandaluz, un polígono suburbial de Barcelona, el presidio o el interior de una mina. Aquilatar esta relación recíproca entre canción y lugar ayuda a entender las circunstancias sociales de los colectivos a los que representa y las estructuras territoriales subyacentes de los espacios a lo que alude.

Sin embargo, si el flamenco ha sido un arte tradicionalmente asociado a los proscritos, hay que mostrarse muy cauteloso ante los intentos de apropiación cultural por parte de aquellos a los que solo les interesa su cáscara. Son reconocibles por cuanto que, lejos de preocuparse por su complejo universo rítmico, melódico y compositivo, apelan a la sinécdoque reduccionista de Camarón para arrogarse únicamente la condición liminar y, hasta cierto punto, dramática del flamenco. En los afortunados casos en los que esto no es así, el flamenco se convierte en una lente con la que se capta el mundo y desde la que se proyecta una imagen interiorizada, retrato y reflejo de los grupos humanos que lo interpretan.

En definitiva, tal y como afirma el poeta Caballero Bonald (en Grimaldos Feito, 2010), no se puede entender el flamenco sin su medio ambiente. Por ello, cambian sus significados a medida que cambia el sustrato espacial que lo sustenta. Las periferias urbanas españolas, como uno de esos sustratos primordiales, han experimentado profundas transformaciones físicas y sociales desde mediados del siglo $\mathrm{xx}$, cuando empezaron a tomar forma. Por ello mismo, el flamenco ha transitado desde un rol como termómetro del estigma y la marginación, pasando por ser un mecanismo para el reconocimiento social y la autoestima, hasta convertirse en una plataforma donde amplificar los egos y construir un elogio de la periferia. Los habitantes millennials de estos barrios, barriadas y polígonos obreros, ya sí nativos tras una primera generación de emigrantes, han resignificado los atributos de su lugar de origen por medio de esta música. Ella, como otras tantas expresiones culturales, ha servido para construir un sentimiento de pertenencia colectivo en torno a un lugar respecto del cual se tiene, tras el madurar de los ańos, un arraigo afectivo. 


\section{Referencias bibliográficas}

Abel, D. (Dir.). (2003). Polígono Sur (El arte de Las Tres Mil) [película]. Maestranza Films \& Ideale Audience (España, Francia).

Alfeo Álvarez, J. C. \& González de Garay Domínguez, B. (2011). La ciudad periférica. Paisajes urbanos de marginalidad en el cine español de la Transición. En Actas del II Congreso Internacional de Ciudades Creativas (Tomo II, pp. 777-798). Madrid, 26 al 28 de octubre 2011.

Álvarez Caballero, A. (2004). El cante flamenco. Alianza.

Álvarez, J. (2019, octubre 14). Haze: 'Si salí de Los Pajaritos y estuve en la cárcel, supongo que me respetarán más mis alumnos'. ABC de Sevilla. https://sevilla.abc.es/sevilla/sevi-hazesi-sali-pajaritos-y-estuve-carcel-supongo-respetaran-mas-alumnos-201910130802_ noticia.html

Araüna, N., Tortajada, I. \& Figueras-Maz, M. (2019). Feminist reggaeton in Spain: Young women subverting machismo through 'perreo'. YounG. https://doi. org/10.1177/1103308819831473

Arenas, P. (2016, febrero 10). Haze: 'De la cárcel nace gran parte de lo que soy, pero también de las drogas y los amigos'. 20 Minutos. https://www.20minutos.es/noticia/2668183/0/ entrevista-haze-barr/

Ayuntamiento de Barcelona. (2019). Centre Civic Besòs. https://ajuntament.barcelona.cat/ centrescivics/es/centre-civic/centre-civic-besos

Ayuntamiento de Madrid. (2018). Metodología para la elaboración del indice de vulnerabilidad territorial de barrios $y$ distritos de Madrid y ranking de vulnerabilidad. https:// www.madrid.es/UnidadWeb/Contenidos/Publicaciones/TemaServiciosSociales/ IndiceVulnerabil/indicevulnerabilidad.pdf

Bautista Sánchez, J. I., Gross, K. C. \& Orellana Montero, V. (2013). Batalla por el futuro: la industria discográfica contra la música digital. En J. P. Pérez Rufí (Coord.), Industrias audiovisuales: producción y consumo en el siglo xxi (pp. 156-182). Eumednet.

Becerra, J. (2015, octubre 25). ¿Es este el grupo que adoran tus hijos? La Voz de Galicia. https://www.lavozdegalicia.es/noticia/extravoz/2015/10/23/grupo-adoran-tushijos/00031445600285214103133.htm

Camińas Hernández, T. (2013). Apuntes sobre la realidad social en España a través del prisma cinematográfico de Carlos Saura. En C. Rodríguez Fuentes (Coord.), Desmontando a Saura (pp. 15-30). Luces de Gálibo.

Carballo Villagra, P. (2006). Reggaeton e identidad masculina. Cuadernos Intercambio sobre Centroamérica y el Caribe, 3(4), 87-101. https://dialnet.unirioja.es/servlet/ articulo? codigo $=5089062$

Cappa, G. (2016, mayo 14). El futuro ya pasó. Granada Hoy. https://www.granadahoy.com/ ocio/futuro-paso_0_1026197891.html

Cattan, N. (2006). Centre-Périphérie. En C. Ghorra-Gobin (Dir.), Dictionnaire des mondialisations (pp. 47-49). Armand Colin. https://halshs.archives-ouvertes.fr/file/ index/docid/162580/filename/Centre-Peripherie-dicodef.pdf

Conget, J. M. (2017). Prólogo. En S. López Sanz, Haze. La voz cantante. Renacimiento. 
Costa Mas, J. (2003). Visiones de la ciudad funcional europea y la ciudad blindada norteamericana en el imaginario del celuloide. Scripta Nova: Revista Electrónica de Geografía y Ciencias Sociales, 7(146-037). https://revistes.ub.edu/index.php/ScriptaNova/article/view/675

Covarsí Carbonero, J. (2010). El roman de Flamenca. Universidad de Murcia.

Cresswell, T. (2004). Place: A short introduction. Blackwell.

Cruces Roldán, C. (2002). Más allá de la música. Antropología y flamenco (I): Sociabilidad, transmisión y patrimonio. Signatura.

Cruces Roldán, C. (2003). Más allá de la música. Antropología y flamenco (II): Identidad, género y trabajo. Signatura.

Cruz, N. (2018, diciembre 10). El flamencotón de Daviles de Novelda sacude el polígono. El Periódico de Catalunya. https:/www.elperiodico.com/es/ocio-y-cultura/20181209/ otros-escenarios-posibles-actuacion-daviles-de-novelda-discoteca-boxer-cerdanyola $-7192017$

Dotson-Renta, L. (2015). 'On n'est pas condamnéà l'échec': Hip-hop and the banlieue narrative. French Cultural Studies, 26(3), 354-367. https://doi.org/10.1177/0957155815594068

Espadaler, A. M. (2019). Flamenca. Barcelona: Roca Editorial.

Fernández Salinas, V. (1998). Huellas del pasado y pistas para el futuro en el crecimiento extramuros de la Sevilla contemporánea. En M. Valor Piechotta \& C. Romero Moragas (Coords.), Sevilla Extramuros: La huella de la Historia en el Sector Oriental de la Ciudad (pp. 195-241). Ayuntamiento de Sevilla; Universidad de Sevilla.

Fraile Prieto, T. (2013). Libertad provisional: la convulsión musical del cine español en los años 70. Musiker. Cuadernos de música, 20, 187-205. https:/dialnet.unirioja.es/servlet/ articulo? codigo $=4722467$

French, K. (2017). Geography of American rap: rap diffusion and rap centers. GeoJournal, 82(2), 259-272. https://doi.org/10.1007/s10708-015-9681-z

Gallego, J. I. (2016). Una mirada a la diversidad en las industrias radiofónica y musical en España. CIC. Cuadernos de Información y Comunicación, 21, 139-155. https://doi. org/10.5209/CIYC.52879

Gamboa, J. M. (2005). Una historia del flamenco. Espasa.

Gámir Orueta, A. (2004). La industria cultural en el mundo. Estructura, composición y distribución territorial de los grupos multimedia en Espańa. Cybergeo: European Journal of Geography, (280). http://journals.openedition.org/cybergeo/2549

Gámir Orueta, A. \& Manuel Valdés, C. (2007). Cine y geografía: Espacio geográfico, paisaje y territorio en las producciones cinematográficas. Boletín de la Asociación de Geógrafos Españoles, 45, 157-190. http://age.ieg.csic.es/boletin/45/07-cine.pdf

García Vázquez, C. (2015). La obsolescencia de las tipologías de vivienda de los polígonos residenciales construidos entre 1950 y 1976. Desajustes con la realidad sociocultural contemporánea. Informes de la Construcción, 67(Extra-1), 1-9. http://dx.doi. org/10.3989/ic. 14.045

Gómez Lizarraga, A. (2018, noviembre 28). De 'La maja vestida' a 'Un perro andaluz': Rosalía a través del arte y la cultura espańola. Los 40 . https://los40.com/los40/2018/11/27/ musica/1543323002_655252.html

Gómez, V. A. (2018, febrero 23). Josele Junior: 2018 puede ser el año del 'gitano nigga'. La Opinión de Málaga. https://www.laopiniondemalaga.es/cultura-espectaculos/2018/02/23/ josele-junior-ano-gitano-nigga/988856.html 
Grataloup, C. (2004). Centre/Périphérie. Hypergeo. http://www.hypergeo.eu/spip.php?article10 Grimaldos Feito, A. (2010). Historia social del flamenco. Península.

Grupo aduar. (2000). Diccionario de geografía urbana, urbanismo y ordenación del territorio. Ariel.

Haze. (2003). Los Pajaritos. En Crónicas del barrio (2) [LP]. s.l.: [autoedición, una copia https:// www.youtube.com/watch?v=6mkg2uysiKc].

Hiernaux, D. \& Lindón, A. (2004). La periferia: voz y sentido en los estudios urbanos. Papeles de Población, 10(42), 101-123. https://www.redalyc.org/articulo.oa?id=11204205

Iglesias Pascual, R. (2015). Segregación residencial, concepciones espaciales subjetivas y xenofobia. Cuadernos Geográficos, 54(1), 230-256. https://revistaseug.ugr.es/index. php/cuadgeo/article/view/2525

Labanyi, J., Lázaro囚Reboll, A. \& Ortega, V. R. (2012). Film noir, the thriller, and horror. En J. Labanyi \& T. Pavlović (Eds.), A companion to Spanish cinema (pp. 259-290). Blackwell.

Leal García, J. (2018). Música y cine Quinqui. Contextualización y análisis de la banda sonora de las películas de Eloy de la Iglesia: Navajeros (1980) y Colegas (1982). Cuadernos de Etnomusicologia, 11, 94-123. https://www.sibetrans.com/etno/public/docs/8-julia-leal.pdf

Lenore, V. (2014). Indies, hipsters y gafapastas. Crónica de una dominación cultural. Capitán Swing.

Llácer Moreno-Aurioles, R. (2015). Las Tres Mil. Análisis social y urbanistico de un territorio excluido: Polígono Sur. Documento de trabajo producido por el Comité René Cassin, Sevilla. https://www.arteycompromiso.com/biblioteca-campus-poligono-sur-pueba/

Loma, J. A. (Dir.). (1985). Yo, el Vaquilla [película]. Golden Sun, Jet Films \& InCine S.A. (Еspaña).

López Castellano, R. (2019). Reyes de la gasolinera. La rumba vallecana y el cuerpo biorrumbero de la Transición. En J. Colmeiro \& A. Martínez-Expósito (Eds.), Repensar los estudios ibéricos desde la periferia (pp. 133-145). Ca’ Foscari.

Los Calis. (1986a). Heroína. En ... De la alegría [LP]. Fonomusic (Madrid).

Los Calis. (1986b). Libertad para ti. En ... De la alegría [Lp]. Fonomusic (Madrid).

Los Chichos. (1974). Quiero ser libre. En Ni más ni menos [LP]. Philips Records (Madrid).

Los Chichos. (1981). Bailarás con alegría. En Bailarás con alegría [LP]. Philips Records (Madrid).

Madrigal, S. R. (2019, febrero 28). Los estigmas de las Tres Mil Viviendas, un barrio 'obrero como los demás'. La Voz del Sur. https://www.lavozdelsur.es/los-estigmas-tres-milviviendas-barrio/

Mala Rodríguez. (2003). La Nińa. En Alevosía [LP]. Universal (Madrid).

Maldonado,L.G. (2018, diciembre 10). El viajedeHaze, el rapero flamenco: dela cocaínaylacárcel a dar clases de literatura. El Español. https://www.elespanol.com/cultura/20181210/ haze-rapero-flamenco-cocaina-carcel-clases-literatura/359464560_0.html

Malvárez, R. (Dir.). (2016). Alalá (alegría) [película]. Producciones Singulares (España).

Mas Hernández, R. (1999). Periferias urbanas y nuevas formas espaciales. En R. Domínguez Rodríguez (Coord.), La ciudad: tamaño y crecimiento (ponencias, comunicaciones y conclusiones del III Coloquio de Geografía Urbana) (pp. 201-233). Universidad de Málaga. 
Ministerio de Fomento, España. (2019). Observatorio de la Vulnerabilidad Urbana. https:// www.fomento.gob.es/arquitectura-vivienda-y-suelo/urbanismo-y-politica-de-suelo/ observatorio-de-la-vulnerabilidad-urbana

Monferrer i Celades, J. M. (2013). El Campo de la Bota. Un espacio y una historia. Octaedro.

Morales Gálvez, C. (2020). El mal querer (2018) de Rosalía: semiótica del videoclip "Di mi nombre (Cap. viII: Éxtasis)". Popular Music Research Today, 2(1), 5-23. https://gredos. usal.es/handle/10366/142955

Nel.lo, O. (2004). ¿Cambio de siglo, cambio de ciclo? las grandes ciudades espańolas en el umbral del S. xxi. Ciudad y Territorio, Estudios Territoriales, 36(141-142), 523-542.

Nichols, B. (2001). Introduction to Documentary. Indiana University Press.

Ojeda Rivera, J. F. (2013). Lectura transdisciplinar de paisajes cotidianos, hacia una valoración patrimonial. Método de aproximación. Revista INVI, 28(78), 27-75. http://dx.doi. org/10.4067/S0718-83582013000200002

Oulios, A. (2019, julio 8). Conversación con Maka, una vida marcada por el barrio y por su música. Beatburguer. http://www.beatburguer.com/conversacion-con-maka-una-vidamarcada-por-el-barrio-y-por-su-musica/

Palomares Navarro, O. \& Vives López, M. (2019). Construyendo a "la Rosalía": iconografía para una nueva diosa. Eviterna, 6, 42-53. https://doi.org/10.24310/Eviternare. v0i6.8051

Pareja Eastaway, M. \& Simó Solsona, M. (2006). La renovación de la periferia urbana en España: un planteamiento desde los barrios. En J. Ponce Solé (Coord.), Derecho urbanistico, vivienda y cohesión social y territorial (pp. 107-144). Marcial Pons, Ediciones Jurídicas y Sociales.

Paskual, I. (2013). El Rock en España 1990-2010. Del espíritu olímpico a la Ley del Suelo. En K. Mora \& E. Viñuela (Eds.), Rock around Spain: Historia, industria, escenas y medios de comunicación (pp. 53-69). Universitat de Lleida.

Piñeira Mantinán, M. J. (2010). Expansion and crisis in the neoliberal town planning process in Spain. Semestrale di Studi e Ricerche di Geografia, 22(1), 53-71. http://www.semestralegeografia.org/index.php/sdg/article/view/203

Relph, E. C. (1976). Place and placelessness. Pion.

Reynaud, A. (1981). Société, espace et justice: Inégalités régionales et justice socio-spatiale. Presses Universitaires de France.

Rosalía. (2018a). Malamente (Cap. 1: Augurio). En El mal querer [LP]. Sony Music (Madrid). [Videoclip https://www.youtube.com/watch?v=Rht7rBHuXW8\&].

Rosalía. (2018b). Pienso en tu mirá (Cap. 3: Celos). En El mal querer [LP]. Sony Music (Madrid). [Videoclip https://www.youtube.com/watch?v=p_4coiRG_BI].

Salas, N. (2017, abril 8). Sevilla, "Ciudad de Refugios". El Correo de Andalucía. https:// elcorreoweb.es/aladar/sevilla-ciudad-de-refugios-IN2834208

Samponaro, P. (2009). 'Oye mi canto' ('Listen to my song'): The history and politics of reggaeton. Popular Music and Society, 32(4), 489-506. https://doi. org/10.1080/03007760802218046

Saura, C. (Dir.). (1981). Deprisa, deprisa [película]. Elías Querejeta P.C \& Les Films Molière (Espańa, Francia). 
Serrano, I. (2019, febrero 15). Nyno Vargas: gitano, reguetonero y empresario de éxito. $A B C$. https://www.abc.es/cultura/musica/abci-nyno-vargas-gitano-reguetonero-y-empre sario-exito-201902150057_noticia.html

Steingress, G. (1993). Sociología del cante flamenco. Centro Andaluz de Flamenco (Jerez de la Frontera).

Sweet Barrio. (2019). Amarrao. En Cinema Usera [LP]. MBg (Madrid).

Temes, R. R. (2014). Valoración de la vulnerabilidad integral en las áreas residenciales de Madrid. EURE, 4O(119), 119-149. http://doi.org/10.4067/S0250-71612014000100006

Tickner, A. B. (2008). Aquí en el ghetto: Hip-hop in Colombia, Cuba, and Mexico. Latin American Politics and Society, 50(1), 121-146. http://doi.org/10.1111/j.15482456.2008.00024.x

Tijerita. (1986). Del Sur a Cataluña. En Sueño con las estrellas [LP]. Epic (Madrid).

Torres Gutiérrez, F. J. (2013). Segregación urbana y exclusión social en Sevilla. El paradigma Poligono Sur. Universidad de Sevilla.

Tuan, Y. F. (1974). Topophilia: A study of environmental perception, attitudes, and values. Prentice-Hall.

Urrutia Valenzuela, A. (2007). La música en el barrio como elemento de afirmación identitaria (El ejemplo de Vallecas). Revista de Dialectología y Tradiciones Populares, 62(1), 85-110. http://doi.org/10.3989/rdtp.2007.v62.i1.27

Valenzuela Rubio, M. (1989). Las ciudades. En V. Bielza de Ory (Coord.), Territorio y sociedad en España II. Geografía Humana (pp. 121-172). Taurus.

Van Tongeren, C. (2017). Distinctive culture: Framing flamenco artistry in Polígono Sur El arte de Las Tres Mil by Dominique Abel. Journal of Spanish Cultural Studies, 18(2), 169189. https://doi.org/10.1080/14636204.2017.1308633

Whittaker, T. (2008). No man's land: Transitional space and time in Carlos Saura's Deprisa, deprisa. Bulletin of Hispanic Studies, 85(5), 679-694. https://doi.org/10.3828/ bhs.85.5.6

Willem, L. M. (2008). From the streets to the screen. The music of Madrid in Saura's Deprisa, deprisa. Letras Peninsulares, 21(1), 7-18. https://digitalcommons.butler.edu/facsch_ papers/255/

Zoido Naranjo, F. (2001). La Convención Europea del Paisaje y su aplicación en España. Ciudad y Territorio, Estudios Territoriales, 33(128), 275-281. https://recyt.fecyt.es/ index.php/CyTET/article/view/75029 